\title{
A new treatment design for water contaminated with phenol
}

\author{
Ali Abdul Rahman-Al Ezzi ${ }^{\circledR}$, Salam H. Alhamdiny ${ }^{\circledR}$ \\ Department of Chemical Engineering, Chemical Processing Engineering, University of Technology, Baghdad, Iraq
}

Abstract

Background: Several important designs have been applied to remove toxic and hazardous organic substances like phenol and phenol compounds from wastewater, but there is a need to seek an alternative design to effectively remove organic pollutants from water to less hazardous compounds and a costeffective system.

Methods: A modified internal loop airlift reactor was designed to remove the organic pollutants in synthetic wastewater using an efficient and cost-effective treatment technique by means of a synergistic effect of combination oxidation, stripping, and adsorption. The influence of the current style was experimentally examined in the treatment of synthetic phenol contaminated wastewater. The practical device was tested under different airflow rates range $(2-15 \mathrm{~L} / \mathrm{min})$ through gross difference retention period (5-60 minutes) at a various molar ratio of phenol to hydrogen peroxide ranging from 1:10 to 1:20. Results: It was revealed that the preferred molar ratio of phenol to hydrogen peroxide equals to 1:20. Moreover, the airflow rate is $15 \mathrm{~L} / \mathrm{min}$ with longer retention period of 60 minutes, indicating the maximum removal efficiency $(89 \%)$ of phenol from the synthetic wastewater.

Conclusion: Successful removal of phenol from water by the removal efficiency of $89 \%$ boosts the success of the executed design as well as the scenario of conducting the synergistic processes (stripping, oxidation and adsorption) in one device and also increases the chances of solving environmental problems via treating wastewater before recycling and releasing it into natural water sources.

Keywords: Waste water, Hydrogen peroxide, Oxidation, Stripping, Adsorption, Phenol.

Citation: Rahman-Al Ezzi A, Alhamdiny SH. A new treatment design for water contaminated with phenol. Environmental Health Engineering and Management Journal 2019; 6(3): 185-190. doi: 10.15171/EHEM.2019.21.

\section{Article History:}

Received: 2 March 2019

Accepted: 6 July 2019

ePublished: 9 August 2019
*Correspondence to:
Ali Abdul Rahman-Al Ezzi
Email:

80070@uotechnology.edu.iq

\section{Introduction}

The development in chemical and petrochemical industries, especially in recent decades, has led to increased release of organic chemicals and inorganic pollutants into the environment, while they have harmful effects, on human health and environment (1). Many processes and applications including physical, chemical, and biological processes have been developed to treat or minimize the effects of pollution (2,3). Airlift loop reactor is an effective alternative to conventional treatment systems (stirred tank and bubble column contactors) to remove organic pollutants from wastewater (4-6). Airlift loop reactors can be classified according to several criteria, but according to the literature review it can be classified into two main categories the BC and the ALR, consisting mainly of a cylindrical or rectangular column with a gas distributor at the entrance, usually static without mechanical parts (7). Air is injected as a single energy input through a simple sparger (8-10). Problems arising during advanced processes for conventional wastewater treatment can be solved by the basic features of the air circulation reactors and increased processing efficiency as well as the possibility of combining these reactors and other processes (multistage ALR with biofilm carriers, sequencing batch bioreactor, biofilm system, membrane bioreactor, ultrasonic reactor, oxidation ditch, photo bioreactor, electro coagulation/ electrochemical systems etc) (11). For example, the engineering dimensions of the draft tube play an important role in improving fluid mixing, bubble contraction, and regulation of flow disturbance through periodic rotation in one or more rings (12-14). The integrated biodegradation of aerobic/anaerobic process can be successfully applied in the airlift loop reactor for the treatment of phenol-contaminated wastewater $(15,16)$. Pollutants such as phenol may reach micro scale level when dissolved in water, so the conventional wastewater treatment processes are considered weak due to the difficulty of treating the microorganisms and non-biodegradable compounds as a result of their short retention times (17). In the present study, modern design 
of a developed internal airlift loop reactor accompanied by a synergistic combine system of oxidation, stripping, and adsorption was used to remove of phenol from wastewater. Various substantial parameters like the molar ratio of phenol to hydrogen peroxide, airflow rate, and contact time have been investigated. The purpose of this study was to examine the effectiveness of the application of a modern design of a synergistic combining of oxidation, stripping, and adsorption for the removal of phenol from wastewater.

\section{Materials and Methods}

The granular activated carbon (GAC) was purchased from Didactic Company. With purity of $99.9 \%$, surface area of $1050\left(\mathrm{~m}^{2} / \mathrm{g}\right)$, and solid density of $1.153(\mathrm{~g} / \mathrm{mL})$, GAC was used as an adsorbent. The solid GAC was milled and sieved to three size ranges (75-250, 250-600, and 600-1190 $\mu \mathrm{m}$,). The obtained powder was used in the present study to investigate the impact of particle size of adsorbent on the adsorption process. Activated carbon was washed with distilled water to remove the fine particles and then dried via dryer. Molecular Sieve Type $5 \mathrm{~A}$, “ $\left(\mathrm{Ca}_{4}, 5 \mathrm{Na} 3\right.$ $\left.\left[\left(\mathrm{AlO}_{2}\right) 12\left(\mathrm{SiO}_{2}\right) 12\right] \cdot \mathrm{XH}_{2} \mathrm{O}\right)$ ”, (S.P.A Milano/divisione analitica), calcium with crystalline type $\mathrm{A}$ is an alkaline silicate. Concentrated hydrogen peroxide 35\% volume/ volume, was purchased from GmbH Olloweg (Germany). Pure crystalline phenol (purity: $99.9 \%$, formula $\mathrm{C}_{6} \mathrm{H}_{5} \mathrm{ClO}$, molecular weight: $128.5 \mathrm{~g} / \mathrm{mol}$ ) supplied by SigmaAldrich, was used to prepare the phenol stock solution of $1000 \mathrm{mg} / \mathrm{L}$ by dissolving $1 \mathrm{~g}$ phenol in $\mathrm{L}$ distilled water. Five required concentrations of 10, 20, 50, 100, and 150 $\mathrm{mg} / \mathrm{L}$ were prepared.

The $\mathrm{pH}$ of the solutions was adjusted by adding $0.1 \mathrm{M}$ hydrochloric acid or $0.1 \mathrm{M}$ sodium hydroxide solutions as needed in the study. Figure 1 presents the effects of the scenario of operating the synergistic style as a predicted in suggested design.

Figure 2 shows details of the basic design of the effect of the synergistic system for stripping, oxidation, and adsorption processes in the internal airlift loop reactor. The design was implemented, arranged, and tested in an integrated visible model.

A modified airlift reactor (Figure 2C) manufactured from the Perplex glass was used during all experiments. The reactor contains an outer tube had a dimension of $15 \times$ $150 \mathrm{~cm}$ with a concentric inner draft tube that dimensions of $7.5 \times 120 \mathrm{~cm}$. The active volume of the reactor was 25 L. The inner draft tube was fixed via three support rods at the upper and the lower end of the column to locate it in a focal position at any distance over the base. The upper end of the draft tube with a bed $(7.5 \times 30 \mathrm{~cm})$ containing a porous adsorbent material (granular activated carbon (GAC) and $5 \AA$ molecular sieves) was used to adsorb the phenol in the wastewater. (Figure $2 \mathrm{~A}$ ). The gas dispenser in (Figure 2B) was made from a ceramic materials and the

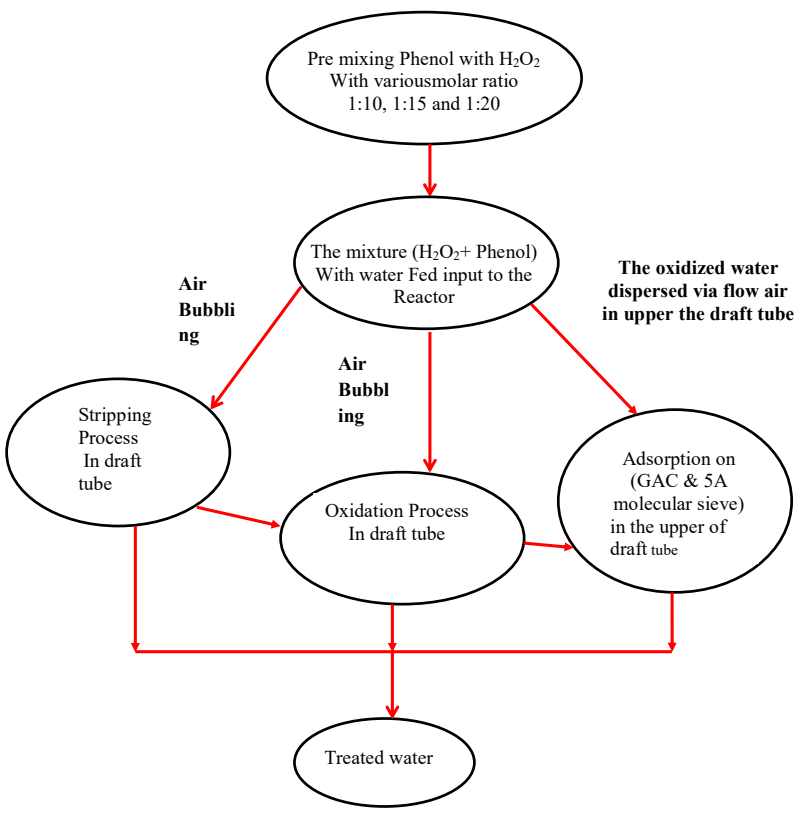

Figure 1. Planning of a synergistic system.

pattern was a multi-puncture stem. The distributor had a valent pore diameter of $0.15 \mathrm{~mm}$ and a free section of $80 \%$ located below the inner tube. The phenol was fed to the loop reactor using gravitational flow while the flow was pre-mixed with polluted water before entering the reactor, and the flow rate was controlled by the gate valves as illustrated in Figure 3. Airflow rate used during the study was between 2 and $15 \mathrm{~L} / \mathrm{min}$. The experiment was conducted at lab temperature $\left(30 \pm 2^{\circ} \mathrm{C}\right)$.

Experimental procedure

Synthetic wastewater contained $150 \mathrm{ppm}$ phenol. The oxidizing agent, $1000 \mathrm{~mL}$ of hydrogen peroxide $\left(\mathrm{H}_{2} \mathrm{O}_{2}\right)$, was added to $4 \mathrm{~L}$ water at $25^{\circ} \mathrm{C}$ in a feed box, so that $0.2 \mathrm{~kg}$ of GAC with $5 \AA$ molecular sieve occupied space of 173.5 $\mathrm{cm}^{3}$. The molar ratio of phenols to hydrogen peroxide was 1:20. The pumping of the synthetic wastewater into the tank was continued at a flow rate of $15 \mathrm{~L} / \mathrm{min}$ while hydrogen peroxide was continuously flowing at a gravitational flow rate. The pressure was kept constant at $\mathrm{P}(\mathrm{abs})=2$ bar. In order to get a steady state for the system, the process required to run for 10 minutes before the experiments.

During the experiments the contains of the reactor was mixed by air flowing through a gas distributor located at the center of bottom of the draft tube (rise zone), causing a difference in the average density of the fluid between both zones (rise and down zone), and inducing oxidized wastewater circulation with a defined cyclic model, to complete the adsorption process, as well as, to complete the stripping and oxidation processes which occur simultaneously. Operating conditions like input and output flow rates from the reactor reached steady 


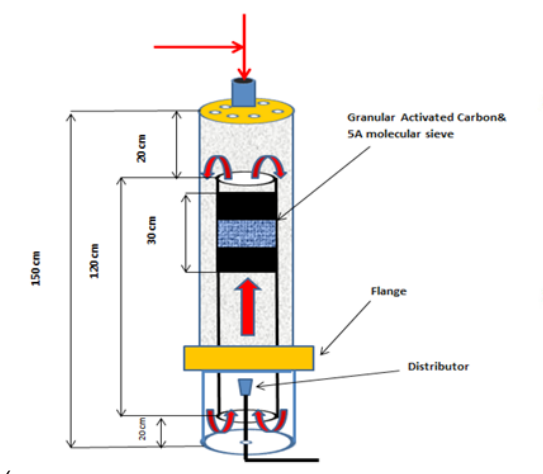

(B)

(c)
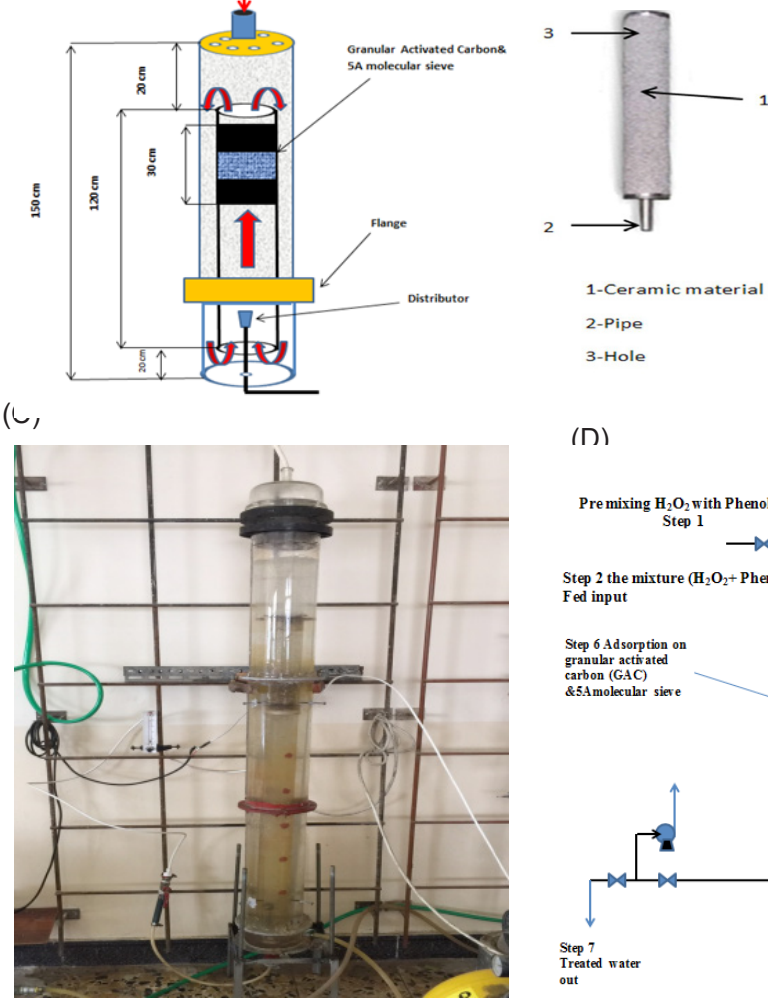

(ח)

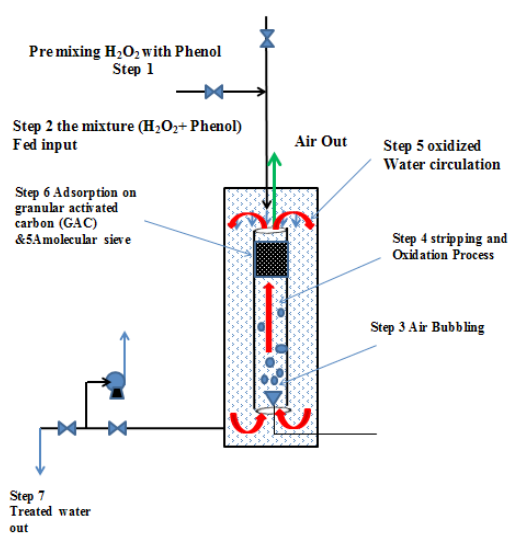

Figure 2. A schematic plan of the synergistic system.

state after 10 minutes by controlling the aperture of the valve located on the pipe using to outflow treated water, and thus, controlling the residence time. The treated

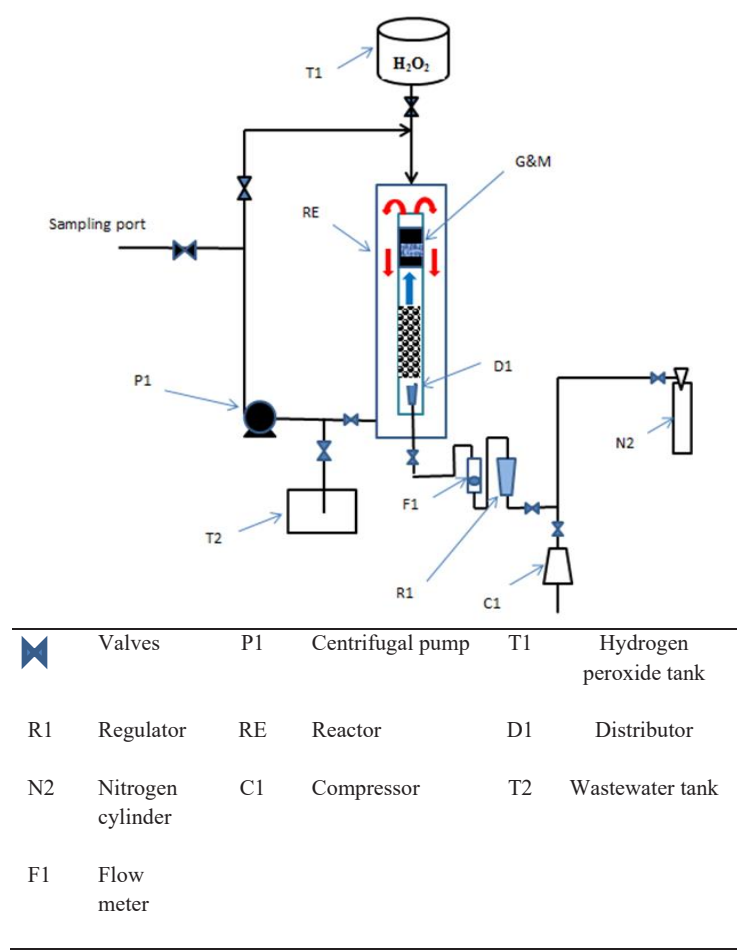

Figure 3. A Schematic diagram of the experimental rig. wastewater was collected after 60 minutes at an outlet port of the loop reactor.

The first experiment was tested for 60 minutes. Twelve samples of oxidized wastewater in a loop reactor were collected 5 minutes intervals for 60 minutes Afterwards, the concentration of phenol in the samples was analyzed by a UV-Vis spectrophotometer (UV-Vis1800 spectrophotometer, Hitachi, Japan) at a wavelength of $270 \mathrm{~nm}$. The same working procedure was repeated with different contact times at different molar ratios of phenol to hydrogen peroxide $(1: 10,1: 15$ and $1: 20)$ with air flow rates of 2-15 L/min, and residence time of 5-60 minutes, to investigate the effectiveness for phenol removal. The experiments were performed at natural $\mathrm{pH}$ of the mixture between 3.5 and 4 . The removal efficiency of phenol from the wastewater was determined as follows:

The percentage of phenol removal was calculated for each run using the following equation:

$E=\frac{C_{i n}-C_{o u t}}{C_{i n}} \times 100$

where $E$ represents removal (\%), $\mathrm{C}_{\text {in }}$ in and $\mathrm{C}_{\text {out }}$ are the initial and final concentrations of phenol in the solution $(\mathrm{mg} / \mathrm{L})$, respectively.

\section{Results}

The effect of synergistic action on stripping, oxidation, and adsorption processes in the scenario of the operation 
of the air loop reactor with the variation in retention period on the percentage of phenol removal from synthetic wastewater are presented in Figure 4. As shown in this figure, by increasing the residence time of polluted water in the reactor, the removal rate increased. The percentage of phenol removal at 150,100,50,20, and $10 \mathrm{ppm}$ for 60 minutes was $89.09 \%, 77.8 \%, 63.6 \%, 43.43 \%$, and $29.29 \%$, respectively.

Figure 5 shows the effect of the variation of the molar ratio of phenolic to hydrogen peroxide, as well as the residence time on the oxidation reaction, and thus, the removal efficiency of phenol from the wastewater. As shown in this figure, the removal percentage of phenol reached approximately $89.09 \%$ at $1: 20$ molar ratio of phenol to $\mathrm{H}_{2} \mathrm{O}_{2}$. Analysis of the results showed that the phenol removal rate improved at the minimum initial molar ratio of phenol to hydrogen peroxide when the airflow rate $(15 \mathrm{~L} / \mathrm{min})$ and the primary concentration of phenol $(150 \mathrm{ppm})$ remain constants. The percentages of phenol removal for molar ratios of $1: 10$ and $1: 15$ at residence time of 60 minutes were 74.2 and $80.1 \%$, respectively (18-21). Figure 6 shows the effects of changes in air flow rates on the circulation time of the polluted liquid and the contact time of contaminated water with the adsorbent substances in the bed during the adsorption process, and thus, the removal efficiency of the phenol from the polluted water.

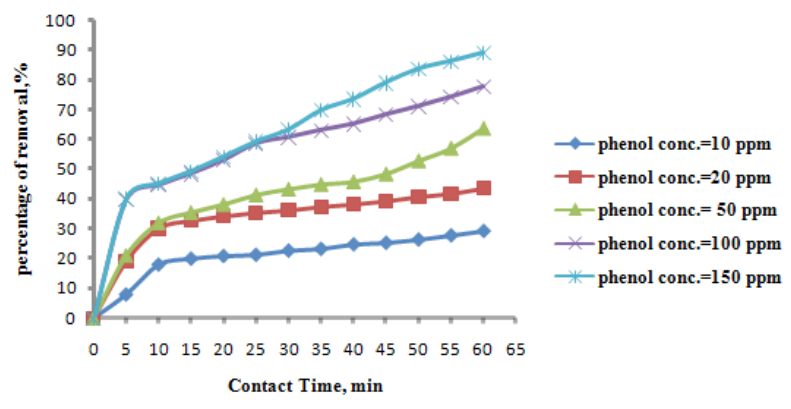

Figure 4. Influence of residence time on the ratio of removal of phenol at different initial concentrations of phenol in an air loop reactor.

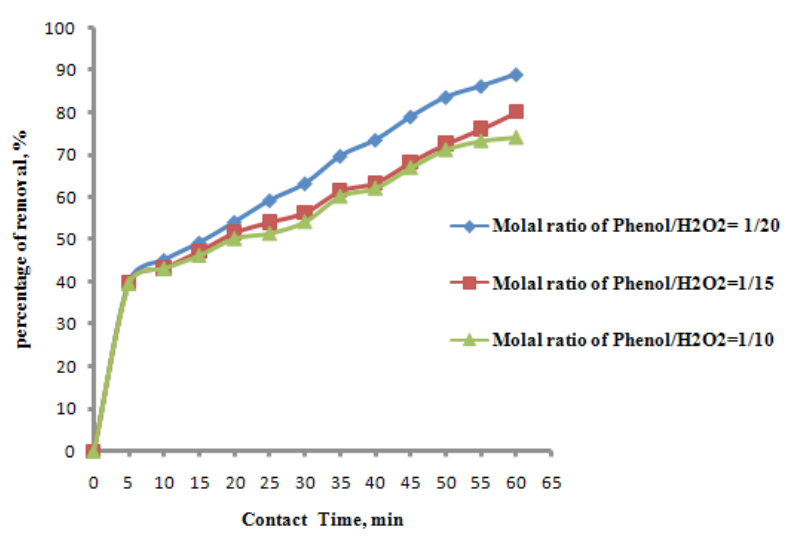

Figure 5. Influence of residence time on the amount of phenol removal with a different molar attribution of phenol to hydrogen peroxide.

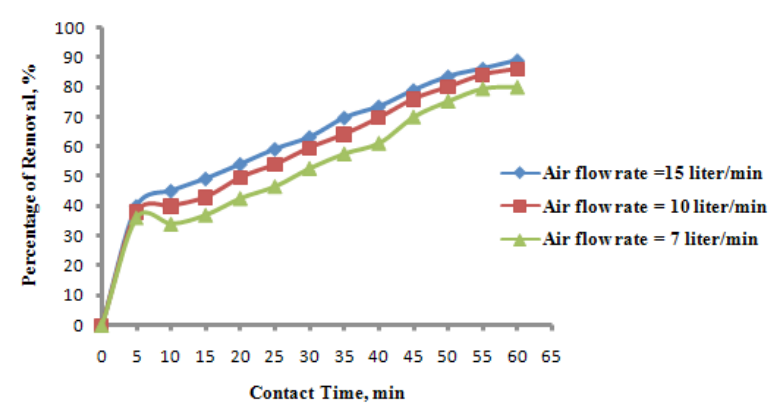

Figure 6. Influence of retention period on the amount of phenol removal with various airflow rates.

There was no increase in the phenol removal rate of more than $8 \%$ was recorded during the residence time range between 50 to 60 minutes where the percentage of removal range between $81 \%$ to $89 \%$, i.e., its approximately constant. Figures 4 to 6 generally show the effect of the conditions and scenario of three synergistic processes of stripping, oxidation, and adsorption on one device as well as the effect of the use of an oxidizing agent $\left(\mathrm{H}_{2} \mathrm{O}_{2}\right)$ alone and exclusive adsorbent material (GAC with $5 \AA$ molecular sieve) on the removal efficiency of phenol from wastewater.

\section{Discussion}

The process of treatment involves the synergy of two physical processes: stripping and adsorption with one chemical reaction. Therefore, the important factor the primary concentration of the pollutant (phenol) had an effective role in creating a large driving force to transfer the pollutant (phenol) from the wastewater to the air in the process of stripping and from the wastewater to the absorbent material (activated carbon particle and molecular sieves) through the process of adsorption, as well as in increasing the rate of phenol degradation in the oxidation process. The characterization of the design of the reactor in this study (synchronization of occurrence of the three processes, and the scenario of the process) had two important effects: The increase of the removal efficiency of phenol from wastewater was considered as a positive effect and inability to determine the percentage of the impact of each process alone on the removal efficiency was considered as a negative effect. When the air flows into the air loop reactor through the pore distributor to create a good mixture of wastewater and hydrogen peroxide solution, hydrogen peroxide decomposes, forming a large number of $\mathrm{OH}^{\cdot}$ free radicals that will attack phenol in the wastewater to break down the hydrocarbon bonds in the oxidation reaction and form the decomposition outputs such as alcohol, water, and carbon dioxide. Air passing through the distributor will dispersed the wastewater, creating a difference in the densities of the air and the dispersed wastewater, resulting in a constant rotation velocity of wastewater that will increase the contact time with the adsorbents materials in the bed extended on the 
top of the internal tube of the loop reactor, which leads to an increase in the efficiency of the adsorption process. Figure 4 shows that the removal rate of phenol at different concentrations of the feed input of the internal loop reactor was higher for the first five minutes compared to the next 5 minutes of the occurrence of the triple synergy processes stripping, oxidation, and adsorption because of the highest difference in phenol concentration between wastewater and air in the process of stripping and phenol concentration in wastewater and absorption materials in the adsorption process in addition to the presence of large numbers of free radicals $\mathrm{OH}^{*}$ at the beginning of the dissolution of hydrogen peroxide for the first 5 minutes of the oxidation reaction time.

One of the most important factors for the success of the adsorption process is the capacity of the bed packed with activated substances (activated carbon and molecular sieves), as well as the empty bed contact time (EBCT), therefore, to obtain the highest removal rate of phenol from wastewater, the full size of the packed bed should be used.

Therefore, the engineering dimensions of the bed $(7.5 \times$ $30 \mathrm{~cm}$ ) represent the optimum size of the mass transfer area in the presence of $0.2 \mathrm{~kg}$ of activated granular carbon and $5 \AA$ molecular sieves. The flow of water contaminated with phenol at an appropriate rate through the confined layer of GAC with molecular sieves $(5 \AA)$ in the packed bed creates a dynamic state that establishes a mass transport area used to reduce the concentration of phenol from the initial level to the final level through recycling contaminated water with the different pressure or density resulting from the partial or total disengagement of the gas from the contaminated water at the top of the draft tube.

This process gives opportunity to complete the adsorption process efficiently. The design of the phenol removal system with the synergistic effect of three processes of stripping, oxidation, and adsorption reduced the cost of designing, constructing, operating, and maintaining three devices in one single-reactor system. The design has been taken into account the requirements of economic feasibility by using the inexpensive material (Plexiglass) to manufacture the phenol removal reactor, also due to its ease of operation and maintenance as well as the less space occupied at a relatively short treatment period (60 minutes), it can be concluded that this system is economically feasible.

\section{Conclusions}

By applying the styling idea in a practical way and according to the results, the following cases can be concluded:

1. Successful design of an air loop reactor that works synergistically for more than a physical or chemical process in one device.

2. The success of the synchronization scenario of the occurrence of the processes of stripping, oxidation, and adsorption in terms of the selection of operating conditions and the concentration of pollutant to oxidant factor, air flow rate, treatment time, and premixing of contaminated water with the oxidizing agent.

3. The removal efficiency of the organic pollutant (phenol) from the water was obtained to be $89 \%$ under the following operational conditions: Air flow rate $=15 \mathrm{~L} /$ minutes, the ratio of phenol to oxidation agent $=1: 20$, and the residence time of 60 minutes.

4. The use of hydrogen peroxide alone as an oxidizing agent is an economically feasible method.

5. In terms of economic perspective, the design is practically done using inexpensive manufacturing materials, it occupies less space, and its maintenance is simple, therefore, it is economically feasible.

6. The outputs of the synergistic system are less hazardous organic compounds in the treated water, which their release in the environment is safer.

\section{Acknowledgments}

The authors would like to gratitude the Lab staff of the Department of Chemical Engineering, University of Technology for their assistance in completing this research.

\section{Ethical issues}

Both researchers involved in the completion of this research and certify that all data collected during the study are presented in this manuscript, and no data from the study has been or will be published separately elsewhere.

\section{Competing interests}

The authors emphasize the full compatibility of opinions and interests, which resulted in the completion of the research in its current form.

\section{Authors' contribution}

Authors participated in all aspects of the research like data collection, analysis, interpretation, and manuscript approval.

\section{References}

1. Aksu Z. Application of biosorption for the removal of organic pollutants: a review. Process Biochem 2005; 40(34): 997-1026. doi: 10.1016/j.procbio.2004.04.008.

2. Farhadian M, Duchez D, Vachelard C, Larroche C. Monoaromatics removal from polluted water through bioreactors-a review. Water Res 2008; 42(6-7): 1325-41. doi: 10.1016/j.watres.2007.10.021.

3. Al Ezzi AA, Najmuldeen GF, kanthasamy R. Trio effects portable water treatment system. Iran J Energy Environ 2015; 6(2): 119-26. doi: 10.5829/idosi.ijee.2015.06.02.07.

4. Nikakhtari H, Hill GA. Toluene vapor remediation in a continuous packed bed loop bioreactor. Environmental Progress 2008; 27(2): 234-41. doi: 10.1002/ep.10253.

5. Vergara-Fernández AO, Quiroz EF, Aroca GE, Alarcón 
Pulido NA. Biological treatment of contaminated air with toluene in an airlift reactor. Electron J Biotechnol 2008; 11(4): 3-4. doi: 10.4067/S0717-34582008000400003.

6. Vunjak-Novakovic G, Kim Y, Wu X, Berzin I, Merchuk JC. Air-lift bioreactors for algal growth on flue gas: mathematical modeling and pilot-plant studies. Ind Eng Chem Res 2005; 44(16): 6154-63. doi: 10.1021/ie049099z.

7. Huang TK, McDonald KA. Bioreactor engineering for recombinant protein production in plant cell suspension cultures. Biochemical Engineering Journal 2009; 45(3): 168-84. doi: 10.1016/j.bej.2009.02.008.

8. Brenner A, Ben-Shushan N, Siegel MH, Merchuk JC. Pilot plant performance and model calibration of a sequencing batch air-lift reactor. Water Sci Technol 1997; 35(1): 121-7. doi: 10.1016/S0273-1223(96)00887-6.

9. Gavrilescu M, Roman RV. Cultivation of a filamentous mould in an airlift bioreactor. Acta Biotechnologica 1995; 15(4): 323-35. doi: 10.1002/abio.370150402.

10. Gavrilescu M, Tudose RZ. Effects of geometry on hydrodynamics in external-loop airlift reactors. Chem Eng Commun 1997; 156(1): 89-113. doi: $10.1080 / 00986449708936671$.

11. Merchuk JC. Airlift bioreactors: review of recent advances. The Can J Chem Eng 2003; 81(3-4): 324-37. doi: 10.1002/ cjce. 5450810301 .

12. Gavrilescu M, Tudose RZ. Modelling mixing parameters in concentric-tube airlift bioreactors part I: mixing time. Bioprocess Eng 1999; 20(5): 423-8. doi: 10.1007/ s004490050610.

13. Gavrilescu M, Tudose RZ. Modelling mixing parameters in concentric-tube airlift bioreactors part II. Axial dispersion. Bioprocess Eng 1999; 20(6): 491-7. doi: 10.1007/ s004490050620.
14. Wei C, Xie B, Xiao H, Wang D. Volumetric mass transfer coefficient of oxygen in an internal loop airlift reactor with a convergence-divergence draft tube. Chem Eng Technol 2000; 23(7): 597-603. doi: $\quad 10.1002 / 1521-4125(200007) 23: 7<597:: a i d-$ ceat $597>3.0 . c 0 ; 2-y$.

15. Chakraborty S, Veeramani H. Response of pulse phenol injection on an anaerobic-anoxic-aerobic system. Bioresour Technol 2005; 96(7): 761-7. doi: 10.1016/j. biortech.2004.08.008.

16. Zhao Z, Jiang G, Jiang S, Ding F. Integrated anaerobic/ aerobic biodegradation in an internal airlift loop reactor for phenol wastewater treatment. Korean J Chem Eng 2009; 26(6): 1662-7. doi: 10.1007/s11814-009-0242-3.

17. Liotta LF, Gruttadauria M, Di Carlo G, Perrini G, Librando V. Heterogeneous catalytic degradation of phenolic substrates: catalysts activity. J Hazard Mater 2009; 162(2-3): 588-606. doi: 10.1016/j.jhazmat.2008.05.115.

18. Glaze WH, Beltran F, Tuhkanen T, Kang JW. Chemical models of advanced oxidation processes. Water Qual Res J 1992; 27(1): 23-42. doi: 10.2166/wqrj.1992.002.

19. Alnaizy R, Ibrahim TH. MTBE removal from contaminated water by the UV/H2O2 process. Desalination and Water Treatment 2009; 10(1-3): 291-7. doi: 10.5004/dwt.2009.690.

20. Beltrán FJ, Ovejero G, Acedo B. Oxidation of atrazine in water by ultraviolet radiation combined with hydrogen peroxide. Water Res 1993; 27(6): 1013-21. doi: 10.1016/0043-1354(93)90065-P.

21. Crittenden JC, Reddy PS, Arora H, Trynoski J, Hand DW, Perram DL, et al. Predicting GAC performance with rapid small-scale column tests. J Am Water Works Assoc 1991; 83(1): 77-87. doi: 10.1002/j.1551-8833.1991.tb07088.x. 